http://jmscr.igmpublication.org/home/ ISSN (e)-2347-176x ISSN (p) 2455-0450 crossref DOI: https://dx.doi.org/10.18535/jmscr/v7i12.104

Journal Of Medical Science And Clinical Research

\title{
Clinical Utility of CBNAAT in the Diagnosis of Pulmonary Tuberculosis - Our Experience
}

Authors

Dr Thammana Sridevi" ${ }^{*}$, Prof. K.V.V. Vijaya Kumar ${ }^{2}$, Dr V. Surya Kumari ${ }^{3}$, Dr B. Padmaja ${ }^{4}$, Dr L.Chakradhar ${ }^{5}$, Dr T.Jahnavi ${ }^{6}$, Dr B.Vidya ${ }^{7}$, Dr B. Swetha ${ }^{8}$, Dr T.S.S.L.Pratyusha9, Dr N.Shashikanth ${ }^{10}$, Dr K.L.Chermisha ${ }^{11}$, Dr A.Arjun ${ }^{12}$, Dr Soundhariyan ${ }^{13}$, Dr B.Girija ${ }^{14}$

*Corresponding Author

Dr Thammana Sridevi

Door. No. 6-15-46/3, B-2, Sea Winds Apartments, East Point Colony, Visakhapatnam - 530017, Andhra Pradesh, India

\section{Abstract}

Introduction: WHO End TB Strategy calls for the early diagnosis of TB and universal drug susceptibility testing (DST). Molecular assays based on nucleic acid amplification techniques such as polymerase chain reaction have been developed for rapid TB diagnosis and are being implemented in developing countries. CBNAAT is cartridge based nucleic acid amplification test an automated polymerase chain reaction test utilizing the GeneXpert platform.

Aim and Objectives: The study aims to determine the clinical utility of CBNAAT in the diagnosis of pulmonary $T B$ in a tertiary care center.

Materials and Methods: 129 cases OF PRESUMPTIVE PTB CASES were included in the study after exclusion criteria. All patients were subjected to routine blood investigations and Sputum, BAL specimens for AFB smear, CBNAAT and liquid cultures. Results were analysed using SPSS software.

Results: Of the 129 cases males were 82 (63.5\%), and females were 47(36.5\%).

The sensitivity, specificity, PPV and NPV of all samples for AFB smear were $54.79 \%, 98.43 \%, 95.24 \%$ and $79.11 \%$ respectively. The sensitivity, specificity, PPV and NPV of all samples for CBNAAT were $84.93 \%, 92.13 \%, 86.11 \%$ and $91.41 \%$ respectively.

The sensitivity and specificity of smear positive, culture positive cases was (26/29) 96.30\% and 100\% with a positive predictive value $100 \%$ and negative predictive value of $66.67 \%$. The sensitivity and specificity of smear negative culture positive cases was 70\%, 92.5\% respectively with a PPV of 70\% and NPV of $92.5 \%$.

Conclusions: CBNAAT has good clinical utility in smear negative culture positive cases both in pulmonary cases. CBNAAT has higher diagnostic efficacy than AFB smear in all pulmonary samples.

Keywords: Pulmonary Tuberculosis, Molecular Diagnostics, CBNAAT, Genexpert.

\section{Introduction}

Tuberculosis (TB) remains a large-scale public health problem. Key global priorities for tuberculosis (TB) care and control include improving case-detection and detecting patients earlier, including patients with smear-negative. The WHO End TB Strategy calls for the early diagnosis of $\mathrm{TB}$ and universal drug susceptibility testing (DST), highlighting the critical role of laboratories 
in the post-2015 era for rapidly and accurately detecting TB and drug resistance. Molecular assays based on nucleic acid amplification techniques such as polymerase chain reaction (PCR) have been developed for rapid TB diagnosis and are being implemented in developing countries ${ }^{(1-8)}$.

India has the highest number of TB cases in the world, with over 2 million active TB cases every year ${ }^{9}$. One fourth of the global incident TB cases occur in India annually ${ }^{10}$. Early and accurate diagnosis is the first critical step in controlling TB. The control of TB is hampered by slow, insensitive diagnostic methods, particularly for the detection of drug resistant forms and in patients with human immunodeficiency virus infection. Early detection is essential to reduce the death rate and interrupt transmission, but the complexity and infrastructure needs of sensitive methods limit their accessibility and effect.

The sensitivity of smear microscopy and its inability to detect drug resistance limits its impact on TB control. Culture methods and drug susceptibility testing is complex, time consuming, taking around 6-8 weeks. While patients await diagnosis, they may be inappropriately treated leading to their disease progression. This results in an increased chance of morbidity from tuberculosis. They continue to transmit drug-resistant TB to others, especially family members and resistance may become amplified $^{11,12}$.

To respond to the urgent need for simple and rapid diagnostic tools in high-burden countries, a new diagnostic test has been developed by Cepheid \& FIND, a rapid, fully automated test based on PCR which detects DNA directly from clinical specimens and also detects rifampicin resistance. This test is designed to purify, concentrate, amplify and identify targeted rpo B nucleic acid sequences, and delivers answers from unprocessed samples in $120 \mathrm{~min}$, with minimal hands on time ${ }^{13,14,15,16}$.

Xpert MTB/RIF is cartridge based nuclic acid amplification test (CBNAAT) an automated polymerase chain reaction test utilizing the GeneXpert platform. Xpert MTB/RIF is a single test that can detect both Mycobacterium tuberculosis complex and rifampicin resistance within 2 hours after starting the assay with minimal hands-on technical time ${ }^{17}$.

The test procedure may be used directly on clinical specimens, either fresh sputum samples or sputum pellets, which are obtained after decontaminating and concentrating the sputum. In both cases, the test material is combined with the reagent and incubated at room temperature for 15 minutes. After incubation, $2 \mathrm{ml}$ of the treated sample are transferred to the cartridge and the run is initiated ${ }^{17}$.

\section{Aims}

The study aims to determine the clinical utility of CBNAAT in the diagnosis of pulmonary $\mathrm{TB}$ in a tertiary care center.

\section{Objectives}

1. To compare the sensitivity and specificity of CBNAAT with AFB smear in the diagnosis of pulmonary tuberculosis.

2. To determine sensitivity and specificity of CBNAAT in smear positive culture positive cases (SPCP) and smear negative culture positive cases (SNCP).

\section{Materials \& Methods}

It is a single center observational study done at a tertiary care hospital where IRL lab facility is there. We have facilities for CBNAAT, LPA, LIQUID CULTURES are available.

Both inpatients and outpatients attending Government chest hospital with presumptive PTB (symptoms of cough more than 2 weeks, fever, chest pain, hemoptysis, loss of weight, loss of appetite) were enrolled in the study after taking informed written consent.

About 129 cases were included in the study after exclusion criteria during a period of 12 months. Demographic data noted for all patients and subjected to following routine investigations.

- Complete blood Profile

- Chest x-ray

- Liver function tests, renal function tests

- ICTC ((Integrated counseling and testing centre) 
Sputum Sample collection- was done as per the standard protocol of RNTCP (Revised national tuberculosis control programme) from patients who has productive cough. And who does not have sputum production induced sputum was collected with 3\% Nacl neubulizations. Sputum samples were sent for AFB smear, sputum CBNAAT and liquid culture- considering it as gold standard. For patients with sputum smear negative bronchoscopy was done and bronchial washings taken and sent for AFB staining, CBNAAT and liquid culture.

The study did not affect the treatment of patients in any manner. Confidentiality was maintained during and after the study owing to the stigma associated with the diseases.Data analysis was done using SPSS software.Statistical analysis done using percentages, mean,standard deviation, sensitivity and specificity formulas.

\section{Results}

Of the 129 cases males were $82(63.5 \%)$, and females were 47(36.5\%). (FIG-1) Maximum number of cases fall in the age group of 20 to 50 years $85(65.89 \%)$, most economically productive age group.(TABLE-1)

Among 129 cases only 29 cases were (both sputum, BAL) smear positive and 100 cases (were sputum, BAL) smear negative. Of the 29 smear positive cases 26 cases have shown positive results with (sputum, BAL) CBNAAT and culture positivity in 27 cases. Only in 2 cases sputum culture was negative. Among the 100 smear negative cases 20 cases were culture positive and CBNAAT could be able to detect M-TB in 20 cases of which only 14 cases were culture positive and 6 cases were culture negative.

Of the total 129 cases Culture positivity was seen in $47 / 129(36.43 \%)$ cases of which $40(85.1 \%)$ cases were detected by CBNAAT and only 26 (20.15\%)cases were detected by smear for AFB. Culture was negative in 82 cases of which 6 cases (false positives) were CBNAAT positive and 76 cases were true negatives. (TABLE-2)

The sensitivity of CBNAAT in bronchial washings is $91.3 \%$ compared to $52.7 \%$ of AFB smear. The specificity of CBNAAT is $93.06 \%$ where as it is $100 \%$ for AFB smear. The sensitivity, specificity and positive predictive value of CBNAAT in sputum are $78.26 \%, 88.89 \%$ and $94.74 \%$ respectively which are higher than that of AFB smear which are $60.87 \%, 77.78 \%$ and $87.5 \%$ respectively. (table -3 ).

The sensitivity, specificity, PPV and NPV of all samples for AFB smear were $54.79 \%$, 98.43\%, $95.24 \%$ and $79.11 \%$ respectively. The sensitivity, specificity, PPV and NPV of all samples for CBNAAT were $84.93 \%, 92.13 \%, 86.11 \%$ and $91.41 \%$ respectively. (Table- 4 ).

The sensitivity and specificity of smear positive, culture positive cases was (26/29) $96.30 \%$ and $100 \%$ with a positive predictive value $100 \%$ and negative predictive value of $66.67 \%$. The sensitivity and specificity of smear negative culture positive cases was $70 \%, 92.5 \%$ respectively with a PPV of $70 \%$ and NPV of $92.5 \%$. (Table- 5).

Table-1: Age Distribution

\begin{tabular}{|l|c|}
\hline Age Group & No. of Cases \\
\hline 0-10 years & 1 \\
\hline 10-20 years & 10 \\
\hline 20-30 years & 20 \\
\hline 30-40 years & 35 \\
\hline 40-50 years & 30 \\
\hline 50-60 years & 20 \\
\hline 60-70 years & 12 \\
\hline$>70$ years & 1 \\
\hline
\end{tabular}

Table-2: Xpert MTB/RIF Assay versus AFB and Culture Status in all Pulmonary Samples

\begin{tabular}{|c|c|c|c|c|c|}
\hline \multirow{2}{*}{\multicolumn{2}{|c|}{$\begin{array}{c}\text { PULMONARY } \\
\text { SAMPLES }\end{array}$}} & \multicolumn{2}{|c|}{ AFB - ve } & \multicolumn{2}{|c|}{$\mathrm{AFB}+\mathrm{ve}$} \\
\hline & & \multirow{2}{*}{$\begin{array}{l}\text { Cultur } \\
\text { e } \\
\text { Positi } \\
\text { ve } \\
14\end{array}$} & \multirow{2}{*}{$\begin{array}{l}\text { Cultu } \\
\text { re } \\
\text { Nega } \\
\text { tive } \\
6\end{array}$} & \multirow{2}{*}{$\begin{array}{c}\text { Cultur } \\
\text { e } \\
\text { Positi } \\
\text { ve } \\
26\end{array}$} & \multirow{2}{*}{$\begin{array}{c}\text { Cultu } \\
\text { re } \\
\text { Negat } \\
\text { ive } \\
0\end{array}$} \\
\hline \multirow{2}{*}{$\begin{array}{l}\text { Xpert } \\
\text { MTB } \\
\text { /RIF }\end{array}$} & $\begin{array}{c}\text { MTB } \\
\text { Detected }\end{array}$ & & & & \\
\hline & $\begin{array}{c}\text { MTB } \\
\text { Not } \\
\text { detected }\end{array}$ & 6 & 74 & 1 & 2 \\
\hline
\end{tabular}


Table-3: Comparision of Sensitivity, Specificity, PPV and NPV OF CBNAAT and AFB Smear in Individual Pulmonary Samples

\begin{tabular}{|l|c|c|c|c|}
\hline $\begin{array}{l}\text { Pulmonary } \\
\text { Samples }\end{array}$ & \multicolumn{2}{|c|}{$\begin{array}{r}\text { BRONCHIAL } \\
\text { WASHINGS }\end{array}$} & \multicolumn{2}{c|}{ Sputum } \\
\hline \multirow{5}{*}{ Sensitivity } & AFB & CBNAA & AFB & GeneXpe \\
& Smear & T & Smear & rt \\
\hline \multirow{5}{*}{ Specificity } & $52.17 \%$ & $91.3 \%$ & $60.87 \%$ & $78.26 \%$ \\
& $(30.59 \%-$ & $(71.96 \%-$ & $(38.54 \%-$ & $(56.3 \%-$ \\
& $73.18 \%)$ & $98.93 \%)$ & $80.29 \%)$ & $92.54 \%)$ \\
\hline \multirow{5}{*}{ PPV } & $100 \%$ & $93.06 \%$ & $77.78 \%$ & $88.89 \%$ \\
& $100 \%)$ & $97.71 \%)$ & $97.19 \%)$ & $91.72 \%)$ \\
\hline \multirow{5}{*}{ NPV } & $100 \%$ & $80.77 \%$ & $87.5 \%$ & $94.74 \%$ \\
& $(73.54 \%-$ & $(60.65 \%-$ & $(61.65 \%-$ & $(73.97 \%-$ \\
& $100 \%)$ & $93.45 \%)$ & $98.45 \%)$ & $99.87 \%)$ \\
\hline & $86.7 \%$ & $97.1 \%$ & $43.78 \%$ & $61.54 \%$ \\
& $(77.52 \%-$ & $(89.92 \%-$ & $(19.75 \%-$ & $(31.58 \%-$ \\
& $93.19 \%$ & $99.65 \%)$ & $70.12 \%)$ & $86.14 \%)$ \\
\hline
\end{tabular}

Table-4: Sensitivity, Specificity, Positive Predictive Value, Negative Predictive Value In AFB SMEAR AND CBNAAT

\begin{tabular}{|l|c|c|}
\hline & AFB Smear & CBNAAT \\
\hline \multirow{3}{*}{ Sensitivity } & $54.79 \%$ & $84.93 \%$ \\
& $(42.70 \%-$ & $(74.64 \%-$ \\
& $66.48 \%)$ & $92.23 \%)$ \\
\hline \multirow{3}{*}{ Specificity } & $98.43 \%$ & $92.13 \%$ \\
& $(94.43 \%-$ & $(86.00 \%-$ \\
& $99.81 \%)$ & $96.16 \%)$ \\
\hline \multirow{3}{*}{ PPV } & $95.24 \%$ & $86.11 \%$ \\
& $(83.84 \%-$ & $(75.94 \%-$ \\
& $99.42 \%)$ & $93.13 \%)$ \\
\hline \multirow{3}{*}{ NPV } & $79.11 \%$ & $91.41 \%$ \\
& $(71.94 \%-$ & $(85.14 \%-$ \\
& $85.17 \%)$ & $95.63 \%)$ \\
\hline
\end{tabular}

Table-5 Comparision of Sensitivity, Specificity, PPV and NPV of CBNAAT in Smear-Postive, Cultutre-Positive and Smear-Negative, Culture Positive Pulmonary Samples

\begin{tabular}{|c|c|c|c|c|}
\hline & \multicolumn{4}{|c|}{ PULMONARY SAMPLES } \\
\hline & $\begin{array}{l}\text { Sensi- } \\
\text { tivity }\end{array}$ & $\begin{array}{l}\text { Speci- } \\
\text { ficity }\end{array}$ & PPV & NPV \\
\hline $\begin{array}{l}\text { Smear } \\
\text { Positive } \\
\text { Culture } \\
\text { Positive } \\
\text { cases }\end{array}$ & $\begin{array}{c}96.30 \% \\
(81.03 \%- \\
99.91 \%)\end{array}$ & $\begin{array}{c}100 \% \\
(15.81 \% \\
-100 \%)\end{array}$ & $\begin{array}{c}100 \% \\
(86.77 \%- \\
100 \%)\end{array}$ & $\begin{array}{l}66.67 \% \\
(9.43 \%- \\
99.16 \%)\end{array}$ \\
\hline $\begin{array}{l}\text { Smear } \\
\text { Negative } \\
\text { Culture } \\
\text { Positive } \\
\text { cases }\end{array}$ & $\begin{array}{c}70 \% \\
(45.72 \%- \\
88.11 \%)\end{array}$ & $\begin{array}{c}92.5 \% \\
(84.39 \%- \\
97.2 \%)\end{array}$ & $\begin{array}{c}70 \% \\
(45.72 \%- \\
88.11 \%)\end{array}$ & $\begin{array}{c}92.5 \% \\
(84.39 \%- \\
97.2 \%)\end{array}$ \\
\hline
\end{tabular}

Fig 1: Gender distribution of all subjects

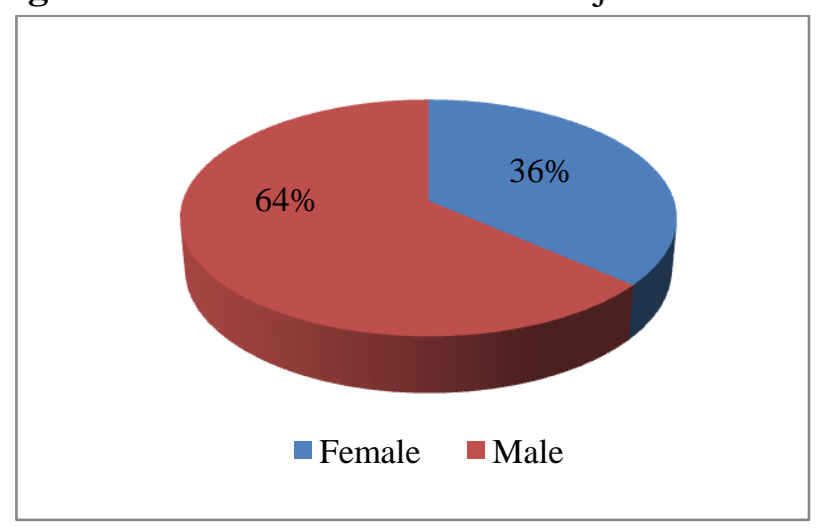

\section{Discussion}

India has the highest TB burden in the world. Early detection of tuberculosis, determining drug resistance and prompt treatment is essential to decrease the spread of disease. CBNAAT, a fully automated test based on PCR, has been approved by WHO for early detection of tuberculosis. In this study, the clinical utility of CBNAAT in the diagnosis of pulmonary tuberculosis has been investigated.

In the present study majority $(65.9 \%)$ of the patients belong to the age group of 20 to 50 years most economically productive age group. Gender and age distribution in the present study were similar to other studies by Arzu et al, Bodmer et al and Rachow et al.

In a study on utility of CBNAAT in bronchial washings by Theron $\mathrm{G}$ et al., ${ }^{18}$ in which only $58 \%$ were detected by smear microscopy compared with 93\% by CBNAAT, the specificity of CBNAAT in bronchial washings was $96 \%$. In this study the sensitivity of CBNAAT in bronchial washings is 91.3\% compared to AFB smear which is only $52.17 \%$ and the specificity of AFB smear and CBNAAT are $100 \%$ and $93.06 \%$ respectively which are compatible with the above study.

In this study the overall sensitivity of CBNAAT was $84.93 \%$ and the specificity was $92.13 \%$, where as for AFB smear, they are $54.79 \%$ and $98.43 \%$ respectively. The overall positive predictive value of CBNAAT and AFB smear are $86.11 \%$ and $95.24 \%$ respectively. The negative predictive value of CBNAAT and AFB smear are $91.41 \%$ and $79.11 \%$ respectively. 
In the present study, the sensitivity of CBNAAT is $96.3 \%$ in smear-positive, culture-positive pulmonary specimens and $70 \%$ in smear-negative, culture-positive pulmonary specimens. The specificity of the test is $100 \%$ in smear-positive, culture-positive cases and $92.5 \%$ in smear-negative, culture-positive cases. In a study done by Arzu NZ et al., ${ }^{19}$ the sensitivity of CBNAAT test was $100 \%$ in smear-positive, culture-positive pulmonary specimens and $74.2 \%$ in smear-negative, culturepositive pulmonary specimens. In another study done by Maynard-Smith L et al., ${ }^{20}$ the pooled summary estimates of sensitivity when testing smear positive and smear negative samples were $95 \%$ and $69 \%$ respectively where as specificities were typically very high up to $98 \%$. In a study done by Bodmer et $\mathrm{al}^{21}$, the sensitivity of the test was $99.8 \%$ in smear-positive, culture-positive pulmonary specimens and 90.2\% in smear- negative, culturepositive pulmonary specimens.

In the previous studies, the sensitivity of the MTB/RIF test for detecting RIF resistance was between 94.4 to $100 \%$ and the specificity was 98.3 to $100 \%$. In our study, CBNAAT detected 12 rifampicin resistance cases.

\section{Conclusion}

CBNAAT has higher sensitivity (84.93\%) than AFB smear $(54.79 \%)$ in all pulmonary samples. The sensitivity of CBNAAT in smear-positive, culturepositive and smear-negative, culture-positive pulmonary samples is $96.3 \%$ and $70 \%$ respectively. This shows that CBNAAT has good clinical utility in smear negative culture positive cases both in pulmonary cases. In bronchial washings, CBNAAT showed a sensitivity of $91.3 \%$ when compared to AFB smear (52.17\%).In sputum, CBNAAT showed a sensitivity of $78.26 \%$ when compared to AFB smear $(60.87 \%)$. The study concludes that CBNAAT has higher diagnostic efficacy than AFB smear in all pulmonary samples.

\section{References}

1. Whitelaw A, Sturm WA. Microbiological testing for Mycobacterium tuberculosis. In:
Schaaf HS, Zumla AI, editors. Tuberculosis. A comprehensive clinical reference. Philadelphia: Saunders; 2009. p. $164 \mathrm{e} 8$.

2. Steingart KR, Henry M, Ng V, Hopewell PC, Ramsay A, Cunningham $J$, et al. Fluorescence versus conventional sputum smear microscopy for tuberculosis: a systematic review. Lancet Infect Dis 2006;6:570e81.

3. Hanna BA, Ebrahimzadeh A, Elliott LB, Morgan MA, Novak SM, Rusch-Gerdes S, et al. Multicenter evaluation of the BACTEC MGIT 960 system for recovery of mycobacteria. J ClinMicrobiol 1999;37: $748 \mathrm{e} 52$.

4. Otu J, Antonio M, Cheung YB, Donkor S, De Jong BC, Corrah T, et al. Comparative evaluation of BACTEC MGIT 960 withBACTEC $9000 \mathrm{MB}$ and $\mathrm{LJ}$ for isolation of mycobacteria in The Gambia. J Infect Dev Ctries 2008;2:200e5.

5. Rabna P, Ramos J, Ponce G, Sanca L, Mane' M, Armada A, et al. Direct detection by the Xpert MTB/RIF assay and characterization of multi and poly drug-resistant tuberculosis in Guinea- Bissau, West Africa. PLoS One 2015;10:e0127536.

6. Togun TO, Egere U, Sillah AK, Ayorinde A, Mendy F, Tientcheu L, et al. Contribution of Xpert() MTB/RIF to the diagnosis of pulmonary tuberculosis among TB-exposed children in The Gambia. Int $\mathbf{J}$ Tuberc Lung Dis 2015;19:1091e7.

7. Gehre F, Antonio M, Otu JK, Sallah N, Secka O, Faal $\mathrm{T}$, et al. Immunogenic Mycobacterium africanum strains associated with ongoing transmission in The Gambia. Emerg Infect Dis 2013;19:1598e604.

8. Piatek AS, Van Cleeff M, Alexander H, Coggin WL, Rehr M, Van Kampen S, et al. GeneXpert for TB diagnosis: planned and purposeful implementation. Glob Health SciPract 2013;1:18e23.

9. Sachdeva KS, Kumar A, Dewan P, Kumar A, Satyanarayan S. New Vision for Revised 
National Tuberculosis Control Programme (RNTCP): Universal access "Reaching the unreached". Ind J Med Res. 2012;135 (5):690-4.

10. India, Ministry of Health and Family Welfare, Central TB Division, Directorate General of Health Services, TB INDIA 2014 Revised National TB Control Programme, Annual status report. 2014.

11. Farmer P, Bayona J, Becerra $\mathrm{M}$, et al. The dilemma of MDR-TB in the global era. Int $\mathbf{J}$ Tuberc Lung Dis 1998; 2:869-76.

12. Van RA, Enarson D. XDR tuberculosis: an indicator of public-health negligence. Lancet 2006; 368:1554-6.

13. "WHO endorses new rapid tuberculosis test", WHO Media center Press release, Geneva, 8 December 2010. [Internet] Available from: www.who.int

/mediacentre/news/releases/2010/.

14. World health organization-policy statement: automated real-time nucleic acid amplification technology for rapid and simultaneous detection of tuberculosis and rifampicin resistance: Xpert MTB/RIF system. Geneva: world health organization, 2011.

15. Robert B, Elizabeth S, Danica H,JoAnn K, Padmapriya B, Michelle RO, et al. Evaluation of the analytical performance of the Xpert MTB/RIF assay. J Clin Microbiol. 2010 Jul; 48(7): 2495-2501.

16. Helb D, Martin J, Elizabeth S, Catharina B, Ellen W, Ken Ho, et al. Rapid detection of Mycobacterium tuberculosis and rifampin resistance by use of on-demand, near-patient technology. J Clin Microbiol 2010 Jan; 48:229-237.

17. Xpert@ MTB/RIF, Two-hour detection of MTB and resistance to rifampicin. CGXMTB/RIF-10, [Internet], 2009 April,

Rev. A. Available from: http:// tbevidence.org/documents/rescentre/sop/Xpe rtMTB_Broch_R9_EU .pdf
18. Theron G, Peter J, Meldau R, Khalfey H, Gina P, Matinyena B, et al. Accuracy and impact of Xpert MTB/RIF for the diagnosis of smear negative or sputum scarce tuberculosis using bronchoalveolar lavage fluid. Thorax. 2013 Nov;68 (11):104351.

19. Arzu NZ, Sezai T, Cengiz C. Evaluation of the GeneXpert MTB/RIF Assay for Rapid Diagnosis of Tuberculosis and Detection of Rifampin Resistance in Pulmonary and Extrapulmonary Specimens. J Clin Microbiol. 2011 Dec; 49(12):4138-4141.

20. Maynard-Smith L, Larke N, Peters JA, Lawn SD. Diagnostic accuracy of the Xpert MTB/RIF assay for extrapulmonary and pulmonary tuberculosis when testing no respiratory samples: a systematic review. BMC Infect Dis. 2014 Dec 31;14 (1):709.

21. Bodmer T, Ströhle A. Diagnosing Pulmonary Tuberculosis with the Xpert MTB/RIF Test. J Vis Exp. 2012; (62): 3547. 